tions, September 13 and October 9-10, showed that the north equatorial band, so inconspicuous for the past four years, had suddenly become one of the darkest and most conspicuous details on the planet, and it suggested that, at the next opposition, the aspect of Jupiter may be found to be considerably transformed.

The Discovery of Gale's Comet, I9I2a.-In No. I, vol. xxiii., of the Journal of the British Astronomical Association Mr. Gale, of Waratah (N.S.W.), tells the story of the discovery of his second comet, Igi2a. Having to travel considerably, he finds but little time for telescopic work, but carries with him a field-glass of 2-in. aperture and a $\times 3$ magnification. Examining the northern part of Centaurus on September 8 , he saw a strange object of obviously cometary character, and on the next evening, having arrived at $\mathrm{Mr}$. Beattie's observatory at Sydney, he was able to confirm the discovery and get a position. At the time of discovery the comet's magnitude was about 6 , and the discovery emphasises the fact that a keen observer under a clear sky may do important work without possessing any considerable instrumental equipment.

A Star Calendar.--We have received a copy of the "Star Calendar," by Mrs. H. Periam Hawkins, for I9I3, and can strongly recommend it to all amateur astronomers. With its revolving disc it enables one to find the position in the sky of any constellation, or the time of rising and setting in these latitudes, for any hour in the year; the price is Is. net. Mrs. Hawkins has also prepared, as in previous years, a "Star Almanac," which contains a great deal of useful information frequently needed. In addition to star charts for the four seasons, various useful tables and notes, the almanac contains a reproduction of Dr. Wolf's photograph of the "Butterfly" nebula of the Pleiades, and quotes Sir Norman Lockyer on the employment of the stars as guides to travellers; the price is $6 d$. net, and both calendar and almanac are published by Messrs. Simpkin, Marshall, Hamilton, Kent and Co.

The Spectroscopic Binary $\beta$ Scorpionis.-In igo8 Dr. Slipher found that the calcium lines in the spectrum of $\beta$ Scorpionis did not appear to partake of the oscillations of velocity shown by the other lines, and, also, that they were sharply defined instead of being broad and diffuse, as are the other lines.

The inquiry as to this peculiar behaviour has been taken a step further by Mr. J. C. Duncan, who, in No. 54 of the Lowell Observatory Bulletins, discusses a large number of new measures of the spectrum carried out by him. The elements which best represent the orbit give a period of 6.8284 days, an eccentricity of $0^{\circ} 27$, and a projected semi-major axis of $10,990,000 \mathrm{~km}$. for the brighter, and $14,450,000$ for the fainter, component; the semi-amplitude of the velocity curve for the brighter star of the system is $126 \mathrm{~km}$. per sec., and for the fainter star $166 \mathrm{~km}$. per sec.

While the velocity of the centre of mass of the system is $-8.0 \mathrm{~km}$. per sec., that given by the calcium radiation, $\mathrm{K}$, is $-16.6 \mathrm{~km}$. per sec., thus showing a difference of more than $8 \mathrm{~km}$. per sec., which seems too great to be attributed to errors of measurement. This seems to support Hartmann's suggested explanation for a similar phenomenon in the case of $\delta$ Orionis, viz. that the calcium absorption is produced by a mass of calcium vapour, independent of the star, moving with a constant velocity between the earth and the star. Observations of other stars in the Scorpio, Orion, and Perseus regions, made by Dr. Slipher, suggest the presence of such calcium clouds in all those regions. On the other hand, a suspected shortening of the period of $\beta$ Scorpionis would sugNo. 2249 , vOI. 90] gest that the calcium cloud envelops the binary system, and produces the effect of a resisting medium on the revolution of the components, but the suspicion needs much more confirmation than is at present forthcoming.

\section{MEDICAL RESEARCH AND PUBLIC HEALTH.}

$\mathrm{N}$ November 28, at a meeting of the General Medical Council, Sir Clifford Allbutt raised the question, how the grant for research provided by the National Insurance Act could be used to the best advantage. He looked forward, not to a crusade against tuberculosis alone, but to a crusade against many other endemic diseases, a "general movement all along the line against all these plagues." He pointed out, very truly, that research, diagnosis, and treatment go hand in hand; that the business of pathological and clinical laboratories, in great cities, is to be in touch with men in practice, and to educate them in the methods of science, and in the results of science. He was opposed to the founding of one large institute in London: he was afraid that it would "harden into a bureau"; he desired to see more use made of the many institutions already founded in diverse parts of the country, in our great cities, and in our university cities. Medical research and medical education are inseparable; the doctor must not regard bacteriological institutes as places where he can put a specimen in the slot and get a diagnosis; he must take an intelligent part in the work of the institute. This view was approved by the General Medical Council.

On November 30, at a meeting of the Metropolitan Asylums Board, a recommendation was made by the Hospitals Committee, "that in view of the continued incidence and fatality of zymotic disease, approval be given to the appointment, at a salary of 50ol. per annum, of a research bacteriologist." Since 1870, the board's hospitals have received more than 500,000 cases of infectious disease, with nearly 40,000 deaths. For one example of the national loss from these diseases, we have the fact that measles alone, in five years, in London, accounts for 10,199 deaths. We want to know more about measles. Probably it would pay the country to appoint more than one bacteriologist, at more than $500 l$. per annum, to study measles alone. We have looked at measles for ages, but have not found the cause of it. The discovery of the cause of diphtheria led to the discovery of diphtheria antitoxin. It is not improbable that some equally valuable discovery is waiting to be made in measles. Dr. Bousfield, at this meeting of the Metropolitan Asylums Board, put the matter in very plain words :-

"We have simply been warehousing infectious disease for years. We have been treating the symptoms and knew nothing about the disease itself. We have spent in forty years $15,000,000 l$, and we now ask that machinery may be set up by which the lives of patients will be saved and the period of their stay in hospital considerably shortened, with a consequent saving of expense to the ratepayers."

This recommendation, of course, was agreed to; and, so far, so good. For in all London there is no authority wiser or more beneficent than the Metropolitan Asylums Board. But what is the good of one bacteriologist? We hope that he will be only the thin end of a wedge of bacteriologists. We are tired of babies dying of measles, tired of our ignorance of the cause of measles. It may be nature's way of killing off the undesirables, but she kills off likewise many desirables, and we want the bacteriologists to take nature in hand. 